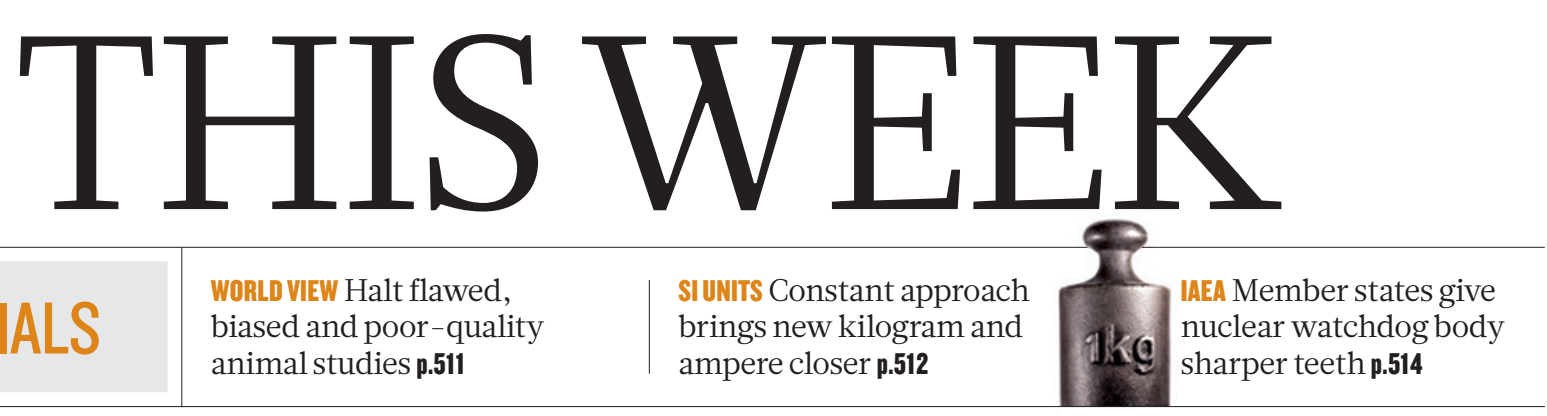

EDITORIALS
Halt flawed, animal studies p.511 brings new kilogram and ampere closer $\mathbf{p} .512$ nuclear watchdog body

sharper teeth $\mathbf{p . 5 1 4}$

\title{
One up, one down
}

\section{Sending satellites to monitor the atmosphere is fundamental to weather and climate research. So why is the United States making such a meal of it?}

$\mathrm{L}$ ate next month, barely four weeks after the remains of its dead upper-atmosphere research satellite rained into the Pacific Ocean, the United States is scheduled to send a new mission into polar orbit. A joint project of NASA and the National Oceanic and Atmospheric Administration (NOAA), the spacecraft is to provide basic information for meteorologists. It will also ensure a continuing flow of data to climate researchers, as they have come to expect.

There should be nothing remarkable about this. But the truth is that the scheduled 25 October launch of the awkwardly named NPOESS Preparatory Project (NPP) represents a landmark achievement for the United States' long-troubled polar satellite programme. As recent discussions on Capitol Hill have made apparent, it remains utterly unclear what will follow the launch, and when.

This odd situation has its roots in the 1994 decision by the administration of president Bill Clinton to merge separate defence and civilian programmes into a single National Polar-orbiting Operational Environmental Satellite System (NPOESS).

What seemed a logical decision instead saw the programme spiral into a bureaucratic nightmare involving NOAA, NASA and the Department of Defense. In the end, it fell to President Barack Obama to dismantle the programme entirely and start again. More than a year later, NOAA and NASA are restoring order to the newly restructured Joint Polar Satellite System. (The same cannot be said for a separate component retained by the defence department, which remains in limbo.)

The challenge now, of course, is money. Overall programme costs have more than doubled the original US\$7-billion estimate, with NOAA alone predicting costs of nearly $\$ 12$ billion to 2024. Even with this, expected goals have been scaled back and delayed.

With funding flat for the programme in 2011, NOAA now wants $\$ 1.1$ billion in fiscal year 2012, an increase of $\$ 688$ million, to get the next polar satellite ready for launch in late 2016 or early 2017 . And if Congress fails to provide - well, the agency threatens, Americans will have to suffer the consequences of a significantly degraded weather-forecast system. Citing storms such as Hurricane Irene, which hammered the US East Coast in August, NOAA assistant administrator Kathryn Sullivan says that these satellites provide "critical environmental intelligence".

All of this leaves lawmakers on Capitol Hill rightly confused. Democrats and Republicans alike support the programme, yet are understandably wary and angry about NOAA's ongoing failure to provide a complete rundown of the budget going forward. House and Senate appropriations committees did their best to find the money, but that doesn't mean much in a volatile year such as this one. As Paul Broun, the Georgia Republican who chairs the House Science Subcommittee on Investigations and Oversight, warned NOAA last week, Congress might not pass any funding bills at all, and instead might maintain current spending levels into 2012 and perhaps 2013. And on top of

that, a high-profile congressional panel is busy looking for further savings to reduce the US debt.

NOAA deserves credit for setting the satellite programme back on an even keel, but the agency will need to provide more than dire warnings of disaster and human suffering if the requested funding doesn't come through. Nor does it help when the agency fails to meet legitimate demands for information from lawmakers - and the press. In fact, on the evidence of Nature's rebuffed enquiries, it seems harder to get information out of NOAA than from

"NOAA should do as its supporters

in Congress suggest, and prepare a proper budget for the programme." the Department of Energy's nuclear weapons "programme. NOAA should do as its supporters in Congress suggest, and prepare a proper budget for the programme, including contingency plans in case funds fail to materialize.

Some options exist. Lawmakers are already thinking about ways in which NOAA can charge for some of the services it provides for other agencies and institutions. This might be an effective way to spread some of the pain, but if the agency moves in this direction it should be for value-added services only. The raw satellite data themselves must remain freely available, both at home and abroad.

In the meantime, fingers are being kept firmly crossed that the NPP satellite makes it safely into space and performs as well as its predecessors. Beyond that, well, NASA officials say they have no reason to believe that the satellite's sensors are going to suddenly shut down at the end of their mission life, as NOAA has implied in its push for a successor. Indeed, many satellites run for years beyond their scheduled lifetime. It would be foolhardy to run a programme on this basis, but it may yet come to that.

\section{Blackened names}

\section{Canada should make public the identities of researchers who commit misconduct.}

W hen government agencies redact material from released records, there are inevitably questions. That was certainly the case on 19 September, when Margaret Munro, a reporter for Postmedia News in Canada, revealed details of several seemingly egregious cases of misconduct that she had obtained under Access to Information laws.

The heavily censored documents, released by the Natural Sciences and Engineering Research Council of Canada (NSERC), the country's 